\title{
Efficacy of Fluoride Varnish and Casein Phosphopeptide-Amorphous Calcium Phosphate for Remineralization of Primary Teeth: A Randomized Clinical Trial
}

\author{
Mahtab Memarpour $^{\mathrm{a}}$ Ebrahim Fakhraei ${ }^{\mathrm{b}}$ Shorangize Dadaein ${ }^{\mathrm{b}}$ \\ Mehrdad Vossoughic ${ }^{c}$

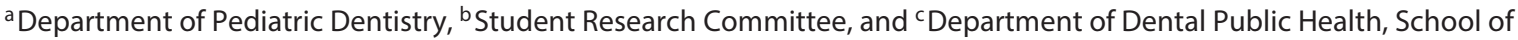 \\ Dentistry, Shiraz University of Medical Sciences, Shiraz, Iran
}

\section{Key Words}

Early childhood caries · Fluoride varnish · Casein

phosphopeptide-amorphous calcium phosphate $\cdot$ Primary teeth

\begin{abstract}
Objective: We aimed to evaluate the efficacy of oral hygiene instruction, fluoride varnish and casein phosphopeptideamorphous calcium phosphate (CPP-ACP) for remineralizing white spot lesions (WSL), and the effect of these on the $\mathrm{dmft}$ index in primary teeth. Subjects and Methods: In this 1-year, randomized clinical trial, 140 children aged 12-36 months with WSL in the anterior maxillary teeth were selected and randomly divided into 4 groups of 35 children each. Group 1 (control) received no preventive intervention. In group 2, there was oral hygiene and dietary counseling. In group 3, there was oral hygiene and the application of fluoride varnish at 4, 8 and 12 months after baseline. In group 4, there was oral hygiene and tooth mousse was applied by the parents twice a day over a 12-month period. At baseline and 4, 8 and 12 months after the intervention, the size of WSL in millimeters and the $\mathrm{dmft}$ index were recorded. One hundred and twenty-two children completed the study. Data were analyzed using the repeated-measures ANOVA test. Results:
\end{abstract}

In group 1, the mean percent WSL area and dmft index values had increased significantly at 12 months after baseline $(p<0.001)$. The interventions led to significant decreases in the size of the WSL; the greatest reduction was in group 4 (63\%) followed by group 3 (51\%) and group 2 (10\%) after 12 months. The smallest increase in the $\mathrm{dmft}$ index was in group 4 (0.17), followed by groups $3(0.3)$ and $2(0.42)$. However, there were no significant differences between the groups $(p<0.001)$. Conclusions: Oral hygiene along with four fluoride varnish applications or constant CPP-ACP during the 12month period reduced the size of WSL in the anterior primary teeth and caused a small increase in $\mathrm{dmft}$ index values.

(c) 2015 S. Karger AG, Basel

\section{Introduction}

Severe early childhood caries (SECC) is defined as 'any signs of caries, either cavitated or noncavitated, on the smooth surface of primary teeth in children younger than 3 years' [1]. A number of studies have documented that $9.5-32.19 \%$ of children experience SECC $[2,3]$.

Prolonged bottle-feeding with milk or sweet liquids during sleep can lead to enamel demineralization and the caries process. Initially, the demineralized lesions appear

\begin{tabular}{ll}
\hline KARGER 125:s & $\begin{array}{l}\text { ( ) 2015 S. Karger AG, Basel } \\
1011-7571 / 15 / 0243-0231 \$ 39.50 / 0 \quad \text { Karger }\end{array}$ \\
$\begin{array}{l}\text { E-Mail karger@karger.com } \\
\text { www.karger.com/mpp }\end{array}$ & $\begin{array}{l}\text { Thisis an Open Access article licensed under the terms of the } \\
\text { Creative Commons Attribution-NonCommercial 3.0 Un- } \\
\text { ported license (CC BY-NC) (www.karger.com/OA-license), } \\
\text { applicable to the online version of the article only. Distribu- } \\
\text { tion permitted for non-commercial purposes only. }\end{array}$
\end{tabular}

Mahtab Memarpour, DMD, MScD

Department of Pediatric Dentistry, School of Dentistry

Shiraz University of Medical Sciences

Ghomabad, Ghasredasht, Shiraz (Iran)

E-Mail memarpour@sums.ac.ir 
as white spot lesions (WSL) on the cervical margins of the maxillary primary incisors [4]. The early stages of decay are slow, so it is beneficial to slow or reverse enamel demineralization before the noncavitated lesion becomes a cavity [5]. Remineralization can be achieved using noninvasive methods that are effective in very young children, e.g. the use of products that contain fluoride, calcium and phosphates, combined with oral hygiene [6$11]$.

Enhanced oral hygiene plays a significant role in preventing SECC $[6,7]$. Studies have shown that using fluoride varnish, together with oral hygiene practices and dietary counseling, leads to the remineralization of WSL [2, $5,8]$ and decreases early childhood caries (ECC) $[1,9]$. Fluoride acts via two main mechanisms: its bacteriostatic effect and enhanced enamel remineralization by the absorption of fluoride on the porous subsurface of the lesion area and the formation of fluoroapatite crystals [8]. Although fluoride enables enamel remineralization, the presence of calcium and phosphate ions in the supragingival plaque is also necessary to promote the process [5]. On the basis of the high levels of these ions available in milk and its derivatives, a new product has been introduced that contains a milk protein nanocomplex (casein phosphopeptide, CPP) which stabilizes amorphous calcium phosphate (ACP) and forms CPP-ACP complexes that can enter the subsurface of demineralized early enamel lesions [5] and remineralize them [10, 11].

To our knowledge, there are no clinical studies to date that compare these noninvasive preventive methods in very young children. This study compared the clinical efficacy of fluoride varnish and a CPP-ACP product in preventing the $\mathrm{dmft}$ index values and enabling the remineralization of WSL in the enamel of primary teeth in young children.

\section{Subjects and Methods}

The research protocol was approved by the Human Ethics Review Committee of the Faculty of Dentistry, Shiraz University of Medical Sciences, and the Iranian Registry of Clinical Trials (code: IRCT201207077402N2). For this 1-year, parallel, double-blind, randomized, controlled clinical trial, 140 children were enrolled at 4 local public health care centers in Shiraz. The inclusion criteria were: an age of between 12 and 36 months at the time of recruitment, having lived since birth in towns with a similar water fluoridation level $(<0.7 \mathrm{ppm})$ and if the parents planned to reside in the same town for the 12 months after recruitment. All participants had at least 4 erupted maxillary primary incisors. WSL were present in at least 2 teeth, and none of the teeth showed signs of cavitated caries [9].
Children who did not use any oral hygiene methods, fluoridecontaining products or other preventive measures at home or at dental clinics were not included in the study. Other exclusion criteria were a history of systemic disease, congenital physical or mental disability, oral or dental anomalies or disabilities, a history of drug allergies, allergies to milk protein or benzoate preservatives and no parental consent to participate in the research. The purpose and methods of the study were described for the parents and they all provided written informed consent. The parents were asked to follow the instructions given to them, to attend regular appointments with their children and to not visit or obtain care from other dentists during the study period.

The 140 children were randomized into 4 groups with 35 in each group, based on a type I error rate of $\alpha=5 \%$ and a power of $1-\beta=80 \%$, in accordance with a study by Almeida et al. [12]. At baseline and follow-up appointments, a staff member at the health clinic selected children by means of a block randomization method with the help of a random number table. All dental examinations were conducted between June 2012 and June 2013. Recruitment started in June 2012 and was completed within 2 months.

\section{Evaluation of WSL}

Dental Examination

Two dentists (E.F. and S.D.) performed all of the dental examinations at the baseline and follow-up appointments. To ensure consistency, a pretest was done by both examiners, who first recorded WSL in 20 children and were given instructions on how to perform the examination and apply the varnish. The teeth surfaces were cleaned with a finger brush and then wiped with a cotton roll and air-dried.

At baseline, an intraoral examination was performed with a disposable mirror and head-light [4]; the location and size of WSL were recorded with a scored dental probe, and the area was then calculated and recorded. For each child, the dmft index was recorded. This index is defined as ' $d$ ' which indicates a decayed tooth, ' $\mathrm{m}$ ' a missing tooth due to decay and ' $\mathrm{f}$ a filled tooth. The classification of WSL used in this study is shown in table $1[4,13]$. As changes in WSL size are important to assess dental caries, this size was recorded in each group at each follow-up appointment [16].

\section{Follow-Up}

The examiners and the parents were blinded as to which group each child had been randomly assigned. At each follow-up appointment, one of the examiners first measured WSL and then recorded the $\mathrm{dmft}$ index. One of the preventive methods was applied by the other examiner (detailed below). Follow-up appointments were scheduled for each child at 4,8 and 12 months after the baseline examination. During follow-up, 18 children were excluded from the study (fig. 1). For groups 2, 3 and 4, in order to review the oral health instructions given to the parents, each child was seen by the dentist every 3 weeks during the first 3 months. After this 3-month period, in each group, the intervention proceeded as detailed above, and each child received a new toothbrush every 4 months. If the preventive treatment failed and any cavitated lesions were observed, the parents were referred to treatment for the caries. The patients in the control group also received oral health instructions and the application of fluoride varnish after completing the study. 


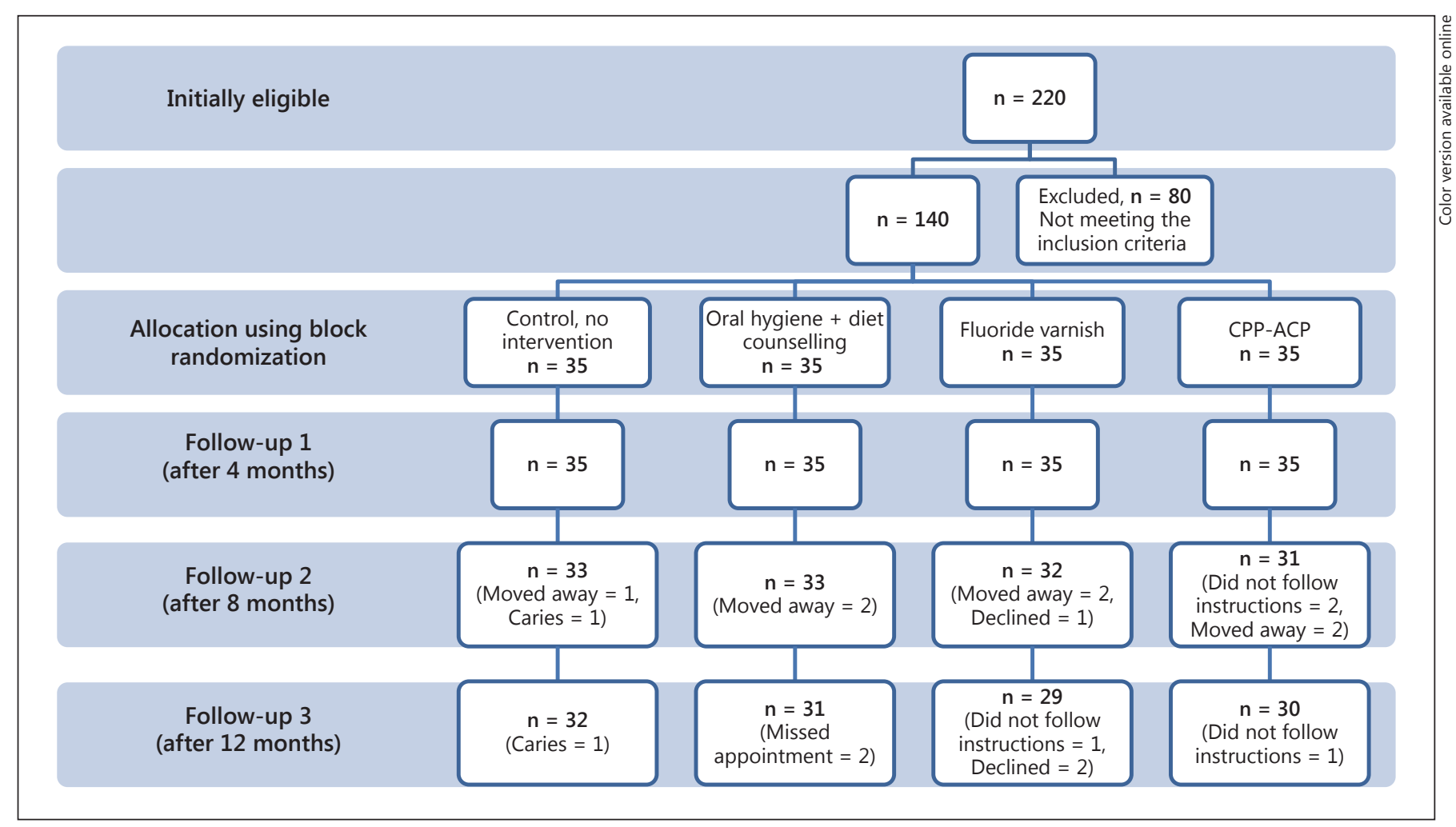

Fig. 1. Flow diagram of study participants and research methodology.

Table 1. Classification used for dental caries $[4,13]$

\begin{tabular}{lll}
\hline Smooth surface & Noncavitated lesions & Cavitated lesions \\
\hline Appearance/color (enamel) & Chalky/white & Chalky white with darker center \\
Surface & Intact & Cavitated dentin loss of tooth structure \\
Tactile & Normal (tactile exam usually not necessary) & Soft \\
Location & Usually adjacent to gingival margin & Usually adjacent to gingival margin \\
\hline
\end{tabular}

\section{Experimental Groups}

For group 1 (control), a dental examination was performed at baseline and at 4, 8 and 12 months. The parents did not receive counseling about caries prevention methods. As a placebo, a water-based, colored solution in a colored container was brushed over the teeth surfaces. The solution was tasteless and odorless, and was similar in color to the fluoride varnish used in group 3.

For group 2 (oral hygiene), at the first visit, the parents received a free gift bag containing an educational pamphlet and a finger toothbrush (Panbehriz, Busher, Iran). The pamphlet explained the factors that influence ECC and provided dietary and feeding advice to prevent SECC, instructions on oral hygiene and information about the importance of caring for primary teeth. The parents were also supplied face-to-face with the oral health instructions in the pamphlet [6]. Subsequent appointments were scheduled until the end of follow-up. At each follow-up appointment, there was motivational oral health counseling and any questions were answered.

For group 3 (oral hygiene and fluoride varnish application), the parents received counseling about oral hygiene and diet. The dentist cleaned the teeth by brushing. The teeth were then isolated with cotton rolls, and fluoride varnish containing 5\% sodium fluoride (DuraShield; Sultan Healthcare, Hackensack, N.J., USA) was applied with a disposable brush to all tooth surfaces and left for $1 \mathrm{~min}$. A small amount of varnish was applied on the surface of the 4 anterior primary teeth; in some children more varnish was used for more teeth. The parents were advised to not allow the child to eat rough (abrasive) foods for the rest of the day [14] and to not brush the teeth until the following day [15]. The fluoride varnish was applied every 4 months.

For group 4 (oral hygiene and tooth mousse application), the parents were given instructions on oral hygiene. One tube of tooth 
Fig. 2. Percent changes in white spot lesions (a) and changes in the $\mathrm{dmft}$ index (b) in all experimental groups during 12 months. 1: Control group; 2: oral hygiene and dietary counseling group; 3: oral hygiene and fluoride varnish group; 4: oral hygiene and tooth mousse (CPP-ACP) group.
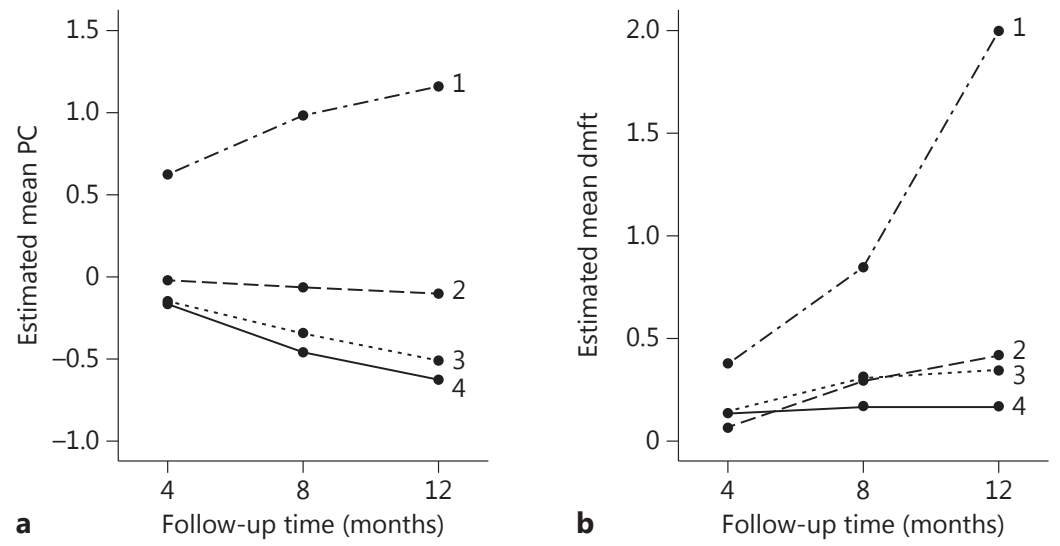

mousse containing CPP-ACP (GC, Tokyo, Japan) was given to the parents. They were advised to apply the mousse with a disposable swab to the entire teeth surface twice a day (in the morning and at bedtime) after the child's teeth had been brushed, and to leave the product in place for at least $3 \mathrm{~min}$. The children were not to be allowed to drink or eat for $30 \mathrm{~min}$, after which they could rinse their mouth. The parents were informed that the tooth mousse was a milk-derived product which was harmless if swallowed. During the study, the parents were given a new tube of tooth mousse on request.

At the first visit, immediately after the fluoride varnish or tooth mousse had been applied, the oral cavity was examined for possible side effects such as gingival inflammation. The parents were asked to wait for $30 \mathrm{~min}$ and then asked if they had observed any side effects. In addition, two phone numbers were given to the parents so that they could inform the dentist of any side effects at any time.

\section{Statistical Analysis}

Demographic variables were compared using the $\chi^{2}$ test and one-way analysis of variance (ANOVA). The percent change (PC) in WSL area was calculated for each child at each follow-up appointment, using the formula: PC = [WSL (at follow-up) - WSL (at baseline)]/WSL (at baseline).

Multisample, repeated-measures RM-ANOVA was used to determine the PC in WSL size and dmft index in each group. Onesample, repeated-measures ANOVA with the Bonferroni correction and one-way ANOVA with the Tukey test were used for between-group and within-group comparisons, respectively. All tests were done at a $\mathrm{p}<0.05$ level of significance.

\section{Results}

At baseline, 140 children (mean age: $21.20 \pm 6.76$ months) with a total of 483 active WSL were enrolled. During follow-up, 18 children were excluded from the study (fig. 1). There were no significant differences be- tween groups in terms of sex ratio $(\mathrm{p}=0.280)$ or mean age $(\mathrm{p}=0.657)$. No side effect or unexpected effects were reported or observed in groups 3 and 4 .

A high level of intraexaminer reliability was achieved for the identification and measurement of WSL according to a weighted kappa statistic of $85 \%$ and an intraclass correlation of $r=0.88$ in 20 randomly selected children.

\section{WSL Changes in All Groups}

The pattern of mean PC in WSL over time was not similar across groups (fig. 2a) or there was a significant interaction effect $(\mathrm{p}<0.001)$.

Between-group comparisons at each time point are denoted by capital letters in the columns of table 2 . For all time points, the mean PC of WSL in group 1 was significantly greater than in the other groups. For example, after 12 months, the mean of WSL area increased by $115 \%$ in group 1 and decreased by approximately $63 \%$ in group 4 , $51 \%$ in group 3 and $10 \%$ in group 2 ( $p<0.001$ for all pairwise comparisons with group 1$)$. However, there were no statistically significant differences between these other groups at 4, 8 and 12 months.

Within-group comparisons at the different follow-up times in each group are shown by lower-case letters in the rows of table 2 . The mean area of WSL in group 1 increased as time increased. The mean (median) PC was $1.15 \pm 1.26(0.79 \%)$ at the end of a 12-month follow-up. The mean after 8 months $(\mathrm{p}=0.001)$ was greater than after 4 months $(\mathrm{p}=0.002)$, but there was no significant difference between months 8 and $12(\mathrm{p}=0.221)$. In groups 3 and 4 , the mean percent WSL area decreased with time. In group 2, there was little change in WSL during the 
Table 2. Changes in mean WSL size in all groups during follow-up $(\mathrm{p}<0.05)$

\begin{tabular}{|c|c|c|c|c|}
\hline \multirow[t]{2}{*}{ Group } & \multicolumn{3}{|l|}{ Follow-up } & \multirow[t]{2}{*}{$\mathrm{p}$ value $^{1}$} \\
\hline & 4 months & 8 months & 12 months & \\
\hline \multicolumn{5}{|l|}{ Control } \\
\hline Mean \pm SD & $+0.62 \pm 1.04^{\mathrm{A}, \mathrm{a}}$ & $+0.98 \pm 1.22^{\mathrm{A}, \mathrm{b}}$ & $+1.15 \pm 1.26^{\mathrm{A}, \mathrm{b}}$ & $<0.001$ \\
\hline Median & 0.36 & 0.67 & 0.79 & \\
\hline Children & 35 & 33 & 32 & \\
\hline \multicolumn{5}{|l|}{ Oral hygiene } \\
\hline Mean \pm SD & $-0.02 \pm 0.41^{\mathrm{B}, \mathrm{a}}$ & $-0.06 \pm 0.78^{\mathrm{B}, \mathrm{a}}$ & $-0.10 \pm 1.12^{\mathrm{B}, \mathrm{a}}$ & 0.594 \\
\hline Median & -0.09 & -0.29 & -0.50 & \\
\hline Children & 35 & 33 & 31 & \\
\hline \multicolumn{5}{|l|}{ Fluoride varnish } \\
\hline Mean \pm SD & $-0.14 \pm 0.36^{\mathrm{B}, \mathrm{a}}$ & $-0.34 \pm 0.48^{\mathrm{B}, \mathrm{b}}$ & $-0.51 \pm 0.56^{\mathrm{B}, \mathrm{c}}$ & $<0.001$ \\
\hline Median & -0.27 & -0.48 & -0.74 & \\
\hline Children & 35 & 32 & 29 & \\
\hline \multicolumn{5}{|l|}{ CPP-ACP } \\
\hline Mean \pm SD & $-0.17 \pm 0.38^{\mathrm{B}, \mathrm{a}}$ & $-0.46 \pm 0.54^{\mathrm{B}, \mathrm{b}}$ & $-0.63 \pm 0.62^{\mathrm{B}, \mathrm{c}}$ & $<0.001$ \\
\hline Median & -0.27 & -0.62 & -0.81 & \\
\hline Children & 35 & 31 & 30 & \\
\hline p value ${ }^{2}$ & $<0.001$ & $<0.001$ & $<0.001$ & \\
\hline
\end{tabular}

\footnotetext{
${ }^{1}$ Within-group comparison using one-sample repeated-measures ANOVA. The results of the Bonferroni test are reported as a lower-case letter in each row.

${ }^{2}$ Between-group comparison using one-way ANOVA. The results of the Tukey test are reported as a capital letter in each column.
}

study period, and no significant differences between the 3 time points $(\mathrm{p}=0.594)$. These data show that the area of WSL increased with time in group 1, remained unchanged in group 2 and decreased in groups 3 and 4 .

\section{dmft Index in All Groups}

There was a significant group-by-time interaction effect for dmft ( $<<0.001$; fig. 2b).

Between-group comparisons at each time point are denoted by capital letters in the columns of table 3.There were significant differences between groups in the mean $\mathrm{dmft}$ index only at the end of the study $(\mathrm{p}<0.001)$. The mean $\mathrm{dmft}$ index in group 1 was higher than that in groups $2-4($ all $\mathrm{p}<0.001)$. The $\mathrm{dmft}$ index after 12 months was lowest in group 4.

Within-group comparisons at the different follow-up times in each group are shown by lower-case letters in the rows of table 3 . The mean $\mathrm{dmft}$ index in group 1 increased as time increased $(\mathrm{p}<0.001)$. The mean $\mathrm{dmft}$ index after 8 and 12 months was greater than after 4 months ( $\mathrm{p}<$ 0.001 and $p=0.015$, respectively), and greater after 12 months than after 8 months $(\mathrm{p}=0.015)$. In groups $2-4$, the mean $\mathrm{dmft}$ index did not change significantly and re-
Table 3. The dmft index in all groups during follow-up

\begin{tabular}{|c|c|c|c|c|}
\hline \multirow[t]{2}{*}{ Group } & \multicolumn{3}{|l|}{ Follow-up } & \multirow[t]{2}{*}{$\mathrm{p}$ value ${ }^{1}$} \\
\hline & 4 months & 8 months & 12 months & \\
\hline Control & $\begin{array}{l}0.37 \pm 1.21^{\mathrm{A}, \mathrm{a}} \\
(\mathrm{n}=35)\end{array}$ & $\begin{array}{l}0.84 \pm 1.69^{\mathrm{A}, \mathrm{b}} \\
(\mathrm{n}=33)\end{array}$ & $\begin{array}{l}2 \pm 2^{A, c} \\
(n=32)\end{array}$ & $<0.001$ \\
\hline $\begin{array}{l}\text { Oral } \\
\text { hygiene }\end{array}$ & $\begin{array}{l}0.06 \pm 0.25^{\mathrm{A}, \mathrm{a}} \\
(\mathrm{n}=35)\end{array}$ & $\begin{array}{l}0.29 \pm 0.86^{\mathrm{A}, \mathrm{a}} \\
(\mathrm{n}=33)\end{array}$ & $\begin{array}{l}0.42 \pm 0.99^{\mathrm{B}, \mathrm{a}} \\
(\mathrm{n}=31)\end{array}$ & 0.055 \\
\hline $\begin{array}{l}\text { Fluoride } \\
\text { varnish }\end{array}$ & $\begin{array}{l}0.14 \pm 0.52^{\mathrm{A}, \mathrm{a}} \\
(\mathrm{n}=35)\end{array}$ & $\begin{array}{l}0.31 \pm 0.89^{\mathrm{A}, \mathrm{a}} \\
(\mathrm{n}=32)\end{array}$ & $\begin{array}{l}0.3 \pm 0.90^{\mathrm{B}, \mathrm{a}} \\
(\mathrm{n}=29)\end{array}$ & 0.070 \\
\hline СРP-ACP & $\begin{array}{l}0.13 \pm 0.43^{\mathrm{A}, \mathrm{a}} \\
(\mathrm{n}=35)\end{array}$ & $\begin{array}{l}0.17 \pm 0.53^{\mathrm{A}, \mathrm{a}} \\
(\mathrm{n}=31)\end{array}$ & $\begin{array}{l}0.17 \pm 0.53^{\mathrm{B}, \mathrm{a}} \\
(\mathrm{n}=30)\end{array}$ & 0.326 \\
\hline $\mathrm{p}$ value ${ }^{2}$ & 0.336 & 0.189 & $<0.001$ & \\
\hline
\end{tabular}

${ }^{1}$ Within-group comparison using one-sample repeated-measures ANOVA. The results of the Bonferroni test are reported as a lower-case letter in each row.

${ }^{2}$ Between-group comparison using one-way ANOVA. The results of the Tukey test are reported as a capital letter in each column. 
mained relatively constant, i.e. near to zero, over time. These results suggest that each of the three interventions effectively prevented the increase in $\mathrm{dmft}$ value after the different follow-up periods.

\section{Discussion}

The methods of preventing dental caries and providing noninvasive intervention that favor the remineralization of decalcified lesions tested in this study showed the beneficial effects of stopping or reversing caries progression. In the control group, which did not receive preventive dental care, the surface area of WSL and the $\mathrm{dmft}$ index increased during the 12-month period of the study, thereby indicating that in untreated teeth, the rate of demineralization was faster than remineralization as previously reported [14]. Compared to the control group, children who received oral hygiene and dietary counseling (group 2) showed no significant increase in WSL size and $\mathrm{dmft}$ index; this confirmed the findings of Wagner et al. [17]. Therefore, oral health education and regular visits to the dentist are considered basic public dental health interventions intended to decrease dental caries [18].

In this study, the finding that educational pamphlets, free toothbrushes, fluoride varnish and tooth mousse were effective confirmed the results of previous studies $[19,20]$. We used direct, repeated instruction to increase the awareness of parents and change their attitude toward dental care for their children $[19,21]$.

WSL decreased in groups 2, 3 and 4 over time; however, the percentage decrease in group 2 was smaller than in groups 3 and 4 . This showed that with time, oral hygiene measures alone were effective in decreasing dental caries but were insufficient to reverse WSL or stop ECC [19].

Our results showed that four periodic applications of fluoride varnish combined with oral hygiene instruction was an effective method to reverse and decrease the WSL area and dmft index after 12 months as previously reported $[14,22]$. Application of fluoride varnish is well accepted by young children, easy and safe and does not take long. It is the most common form of fluoride used to decrease dental caries $[15,22]$. Fluoride is released slowly from the varnish and retards enamel softening [8]. The fluoride ion, in the presence of calcium and phosphate released by enamel demineralization or by dental plaque and saliva, produces fluorapatite, a strong deterrent to demineralization. We used four fluoride applications (because of the advantages over only two applications) on intact enamel $[23,24]$ where WSL form. Ferreira et al. [25] and Almeida et al. [12] re- ported that four fluoride varnish applications reduced WSL in the permanent teeth in school children. Another study showed that using varnish converted $81 \%$ of active enamel lesions to inactive lesions in the primary teeth after 9 months [24], a finding consistent with our results.

In this study, WSL in children who used the tooth mousse decreased with time in a linear fashion. However, the differences between groups 3 and 4 in the PC in WSL size and $\mathrm{dmft}$ index were not significant. The presence of fluoride and the level of calcium and phosphate ions available for remineralization are both important in the reversal of WSL. Products with high levels of ions, such as CPP-ACP, lead to increased remineralization of the subsurface enamel $[7,26]$.

Our results showed that the prolonged use of CPPACP was effective in stopping and reversing WSL in young children as previous reported [10]. These findings are evidence of the long-term benefits of using CPP-ACP [26]. This result may be due to the high level of calcium and phosphate available for remineralization. When fluoride products are used, calcium and phosphate ions may be limited, and this may, in turn, compromise the effectiveness of the fluoride-containing products in preventing ECC $[5,14]$. In agreement with our findings, Zhou et al. [27] concluded that CPP-ACP is more suitable than sodium fluoride for the remineralization of primary teeth. There is evidence that the simultaneous use of CPP-ACP and fluoride is more effective than using fluoride only [28]. However, some other studies claim that these applications do not significantly reduce dental caries $[29,30]$. The differences between studies may be due to differences in sampling, dental care techniques and study design [20]. In our study, we did not use other sources of fluoride because the use of products containing fluoride (e.g. dentifrices) is contraindicated for very young children [5]. In addition, because CPP-ACP was as effective as the fluoride varnish, using CPP-ACP may offer advantages in very young children since it can help reduce the risk of caries without increasing the risk of fluorosis.

The main strengths of our study were its long follow-up period (1 year), its focus on very young children and its use of noninvasive methods (fluoride and CPP-ACP in conjunction with oral health instruction) to achieve reductions in WSL size and dmft index. These straightforward, inexpensive methods can be used by dentists as well as other health center staff members. The main limitations of our study were its limited geographic setting and the possibility that some parents did not follow our recommendation correctly. Another possible limitation is that we did not fully assess all potential caries risk factors in all groups. 


\section{Conclusions}

This study showed that preventive intervention methods play an important role in reducing WSL and dental caries in young children. Oral hygiene instruction alone was not sufficient to reduce WSL and $\mathrm{dmft}$ index values compared to interventions that use fluoride varnish and CPP-ACP. However, oral hygiene instruction together with the application of fluoride varnish and CPP-ACP was an effective method to reduce WSL size and $\mathrm{dmft}$ index values in primary teeth. Prolonged use of CPP-ACP decreased WSL and the dmft index values in primary teeth.

\section{Acknowledgements}

The authors wish to thank the Vice-Chancellor of Research of the Shiraz University of Medical Science, Shiraz, Iran, for supporting this research (grant No. 91-6101). The authors also thank the Dental Research Development Center, Shiraz Dental School, for the statistical analysis and K. Shashok (AuthorAID in the Eastern Mediterranean) for help with the English in the manuscript.

\section{References}

1 American Academy of Pedodontics and American Academy of Pediatrics: Policy on early childhood caries (ECC): classifications, consequences, and preventive strategies. Chicago, AAPD, 2011.

-2 Bissar A, Schiller P, Wolff A, et al: Factors contributing to severe early childhood caries in south-west Germany. Clin Oral Investig 2014; 18:1411-1418.

3 Kumarihamy SL, Subasinghe LD, Jayasekara $\mathrm{P}$, et al: The prevalence of early childhood caries in 1-2 yr olds in a semi-urban area of Sri Lanka. BMC Res Notes 2011;4:336.

$\checkmark 4$ Arora A, Scott JA, Bhole S, et al: Early childhood feeding practices and dental caries in preschool children: a multi-centre birth cohort study. BMC Public Health 2011;11:28.

5 Reynolds EC: Calcium phosphate-based remineralization systems: scientific evidence? Aust Dent J 2008;53:268-273.

6 Kagihara LE, Niederhauser VP, Stark M: Assessment, management, and prevention of early childhood caries. J Am Acad Nurse Pract 2009;21:1-10.

$>7$ Davies GM, Duxbury JT, Boothman NJ, et al: A staged intervention dental health promotion programme to reduce early childhood caries. Community Dent Health 2005;22: 118-122.

$>8$ Rošin-Grget K, Peroš K, Sutej I: The cariostatic mechanisms of fluoride. Acta Med Acad 2013;42:179-188.

$\checkmark 9$ Douglass JM: Fluoride varnish when added to caregiver counseling reduces early childhood caries incidence. J Evid Based Dent Pract 2011;11:46-48.

10 Ferrazzano GF, Amato I, CantileT, et al: In vivo remineralising effect of $\mathrm{GC}$ tooth mousse on early dental enamel lesions: SEM analysis. Int J Dent 2011;61:210-216.

$>11$ Iijima Y, Cai F, Shen P, et al: Acid resistance of enamel subsurface lesions remineralized by a sugar-free chewing gum containing casein phosphopeptide-amorphous calcium phosphate. Caries Res 2004;38:551-556.
12 Almeida MQ, Costa OX, Ferreira JM, et al: Therapeutic potential of Brazilian fluoride varnishes: an in vivo study. Braz Dent J 2011; 22:193-197

13 Warren JJ, Levy SM, Kanellis MJ: Dental caries in the primary dentition: assessing prevalence of cavitated and noncavitated lesions. J Public Health Dent 2002;62:109-114.

14 Holve S: An observational study of the association of fluoride varnish applied during well child visits and the prevention of early childhood caries in American Indian children. Matern Child Health J 2008;12(suppl 1):64-67.

15 Weyant RJ, Tracy SL, Anselmo TT, et al: American Dental Association Council on Scientific Affairs Expert Panel on Topical Fluoride Caries Preventive Agents. Topical fluoride for caries prevention: executive summary of the updated clinical recommendations and supporting systematic review. J Am Dent Assoc 2013;144:1279-1291.

16 Ferreira JMS, Silva MF, Oliveira AF, et al: Evaluation of different methods for monitoring incipient carious lesions in smooth surfaces under fluoride varnish therapy. Int J Paediatr Dent 2008;18:300-305.

17 Wagner Y, Greiner S, Heinrich-Weltzien R: Evaluation of an oral health promotion program at the time of birth on dental caries in 5 -year-old children in Vorarlberg, Austria. Community Dent Oral Epidemiol 2014;42: 160-169.

18 Honkala E: Primary oral health care. Med Princ Pract 2014;23(suppl 1):17-23.

19 Kowash MB, Pinfield A, Smith J, et al: Effectiveness on oral health of a long-term health education programme for mothers with young children. Braz Dent J 2000;188:201205.

20 Ammari JB, Baqain ZH, Ashley PF: Effects of programs for prevention of early childhood caries. A systematic review. Med Princ Pract 2007; 16:437-442.
21 Williams DM: The research agenda on oral health inequalities: the IADR-GOHIRA initiative. Med Princ Pract 2014;23(suppl 1):52-59.

22 Carvalho DM, Salazar M, Oliveira BH, et al: Fluoride varnishes and decrease in caries incidence in preschool children: a systematic review. Braz J Epidemiol 2010;13:139-149.

23 Weintraub JA, Ramos-Gomez F, Jue B, et al: Fluoride varnish efficacy in preventing early childhood caries. J Dent Res 2006;85:172176 .

24 Autio-Gold JT, Courts F: Assessing the effect of fluoride varnish on early enamel carious lesions in the primary dentition. J Am Dent Assoc 2001;132:1247-1253.

25 Ferreira JM, Aragão AK, Rosa AD, et al: Therapeutic effect of two fluoride varnishes on white spot lesions: a randomized clinical trial. Braz Oral Res 2009;23:446-451.

26 Beerens MW, van der Veen MH, van Beek H, et al: Effects of casein phosphopeptide amorphous calcium fluoride phosphate paste on white spot lesions and dental plaque after orthodontic treatment: a 3-month follow-up. Eur J Oral Sci 2010;118:610-617.

27 Zhou C, Zhang D, Bai Y, et al: Casein phosphopeptide-amorphous calcium phosphate remineralization of primary teeth early enamel lesions. J Dent 2014;41:21-29.

28 Ogata K, Warita S, Shimazu K, et al: Combined effect of paste containing casein phosphopeptide-amorphous calcium phosphate and fluoride on enamel lesions: an in vitro pH-cycling study. Pediatr Dent 2010;32:433438 .

29 Sitthisettapong T, Phantumvanit P, Huebner C, et al: Effect of CPP-ACP paste on dental caries in primary teeth: a randomized trial. J Dent Res 2012;91:847-852.

30 Plonka KA, Pukallus ML, Holcombe TF, et al: Randomized controlled trial: a randomized controlled clinical trial comparing a remineralizing paste with an antibacterial gel to prevent early childhood caries. Pediatr Dent 2013;35:8E-12E. 